\title{
Apresentação rara de schwannoma no tornozelo: Um relato de caso*
}

\section{Rare Presentation of Schwannoma in the Ankle: A Case Report}

\author{
Prateek Kumar Gupta ${ }^{1}$ Ashis Acharya ${ }^{10}$ Shakti Swarup Panda ${ }^{10}$ \\ 1 Departamento de Medicina Esportiva, Sir Ganga Ram Hospital, Nova \\ Delhi, Índia \\ Rev Bras Ortop 2021;56(1):118-120. \\ Endereço para correspondência Prateek Kumar Gupta, MBBS, MS, \\ MCh, FRCS, Departamento de Ortopedia, Sir Ganga Ram Hospital, \\ Sarhadi Gandhi Marg, Old Rajinder Nagar, Nova Deli, 110060, Índia \\ (e-mail: sportsmedicinedelhi@yahoo.com).
}

\begin{abstract}
Resumo
Palavras-chave

- tornozelo

- schwannoma

- localização rara

- relato de caso

Schwannomas são tumores benignos de crescimento lento, e constituem $8 \%$ de todos os tumores de tecido mole. Os sinais clínicos e sintomas são muitas vezes mal interpretados por causa da baixa incidência, e, muitas vezes, esses tumores são mal diagnosticados. Um paciente do sexo masculino de 39 anos apresentou um inchaço solitário não traumático sobre o aspecto posteromedial do tornozelo direito, que aumentou gradualmente de tamanho e estava associado a dor. $\mathrm{O}$ inchaço era clinicamente firme, não flutuante, e não associado a qualquer comprometimento sensório-motor. A excisão cirúrgica do inchaço foi feita sem danificar os vasos e os nervos circundantes. O exame histopatológico do tumor excisado revelou schwannoma.

Schwannomas are benign slow-growing tumors that constitute $8 \%$ of all soft-tissue tumors. The clinical signs and symptoms are often misinterpreted because of the low incidence, and these tumors are often misdiagnosed. A 39-year-old male patient presented with nontraumatic solitary swelling in the posteromedial aspect of the right ankle that gradually increased in size and was associated with pain. Clinically, the swelling was firm, nonfluctuant, and was not associated with sensorimotor impairment. Surgical excision of the swelling was performed without damaging the surrounding vessels and nerves. The histopathological examination of the excised tumor revealed a schwannoma.
\end{abstract}

\section{Introdução}

Schwannomas são tumores benignos de tecido mole, de crescimento lento, que surgem das células de Schwann das bainhas nervosas periféricas. Eles constituem $8 \%$ de todos os tumores de tecido mole. ${ }^{1}$ De todos os casos notificados, entre

Trabalho desenvolvido no Departamento de Medicina Esportiva, Hospital Sir Ganga Ram, Sarhadi Gandhi Marg, Velho Rajinder Nagar, Nova Delhi, Índia.

recebido

29 de Fevereiro de 2020

aceito

15 de Abril de 2020

Publicado online

Setembro 22, 2020
DOI https://doi.org/

10.1055/s-0040-1714224. ISSN $0102-3616$.
$12 \%$ e $19 \%$ estão localizados na extremidade superior, e entre $10 \%$ e $13 \%$, na extremidade inferior. Suas localizações comuns são a superfície flexora das extremidades, o pescoço, o mediastino, o retroperitônio, as raízes posteriores da coluna vertebral, e o ângulo ponto-cerebelar. ${ }^{2}$ Os sinais e sintomas clínicos são muitas vezes mal interpretados por causa da baixa incidência, e muitas vezes os schannomas são mal diagnosticados como outros tumores de tecido mole, como o neurofibroma.

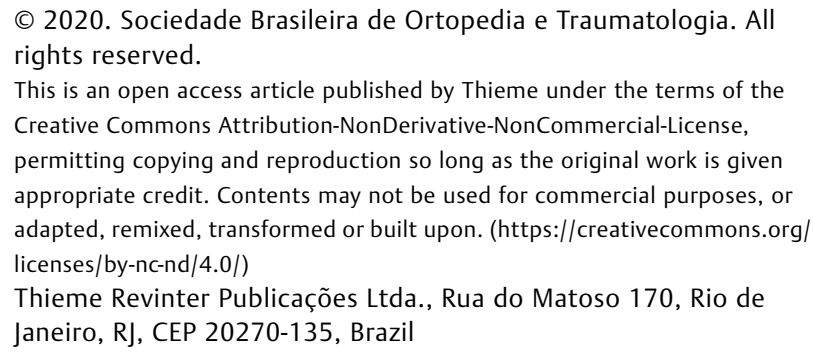

This is an open access article published by Thieme under the terms of the Creative Commons Attribution-NonDerivative-NonCommercial-License, permitting copying and reproduction so long as the original work is given appropriate credit. Contents may not be used for commercial purposes, or adapted, remixed, transformed or built upon. (https://creativecommons.org/ licenses/by-nc-nd/4.0/) Thieme Revinter Publicações Ltda., Rua do Matoso 170, Rio de Janeiro, RJ, CEP 20270-135, Brazil 


\section{Apresentação de caso}

Um paciente do sexo masculino, de 39 anos, se apresentou ao ambulatório com queixas de um inchaço solitário não traumático sobre o aspecto posteromedial do tornozelo direito associado a dor leve. Havia 15 anos que ele tinha notado o inchaço, que aumentou gradualmente de tamanho, e estava associado a dor entre leve e moderada e de natureza intermitente. Não havia histórico familiar significativo.

Os achados clínicos mostraram inchaço firme sobre o aspecto posteromedial do tornozelo medindo aproximadamente $3 \times 2 \times 2 \mathrm{~cm}$, não flutuante, não pedunculado, não compressivo, e sem a presença de transiluminação. Não havia comprometimento sensório-motor na perna direita e no pé.

A ressonância magnética da perna ( - Fig. $\mathbf{1 a , b}, \mathbf{c}$ ) revelou lesão bem circunscrita em plano subcutâneo no aspecto posteromedial do terço distal da perna, encontrando o músculo sóleo e o tendão de Aquiles, sem evidência definitiva de infiltração provável lesão benigna neurogênica?

Prosseguimos com a excisão cirúrgica do inchaço após o devido consentimento e a explicação das complicações. A pele sobre o inchaço foi incisada de forma curva, e a dissecção foi feita para demarcar a cápsula do tumor, que também foi incisada. A dissecção posterior e fina foi feita de modo circunferencial ao longo do ramo do nervo tibial posterior, com a bainha perineural anexada. 0 tumor foi retraído e removido sem danificar os vasos e os nervos circundantes (- Fig. 2a,b).

O nervo foi totalmente preservado e examinado antes do fechamento. 0 tumor excisado foi enviado para estudo histológico ( - Fig. 2c). O período pós-operatório foi tranquilo, com boa cicatrização da pele e nervos bem-preservados.

O exame histopatológico revelou um schwannoma (-Fig. 3) de tipo Antoni $A$, que se caracteriza por células altamente celulares em forma de fuso em volta dos corpos de Verocay, e de tipo Antoni B, consistente de células de Schwann.

a
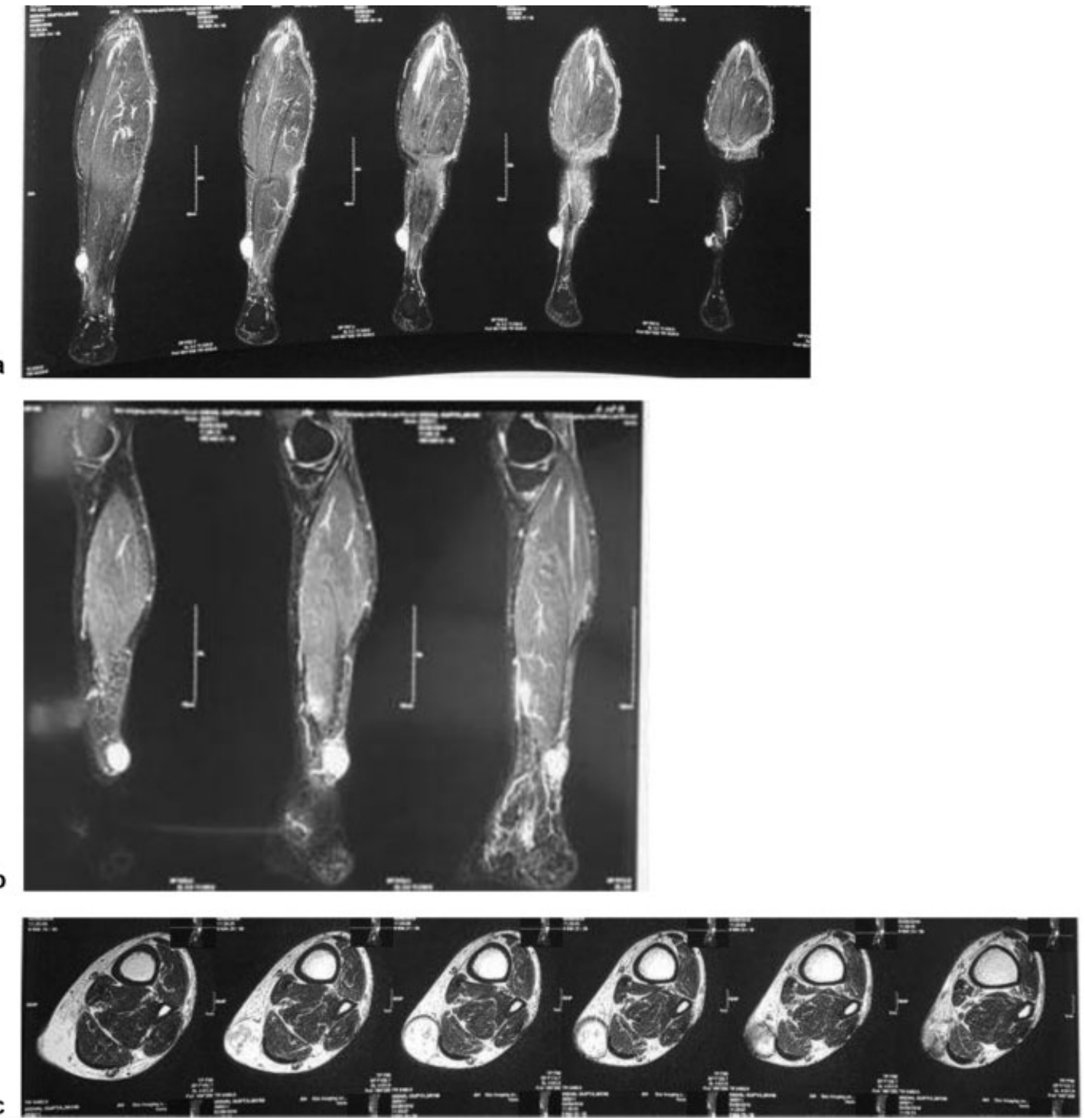

Fig. 1 (a) Ressonância magnética mostrando inchaço posteromedial no terço distal da perna em plano coronal. (b) Ressonância magnética mostrando inchaço posteromedial no terço distal da perna em plano sagital. (c) Ressonância magnética mostrando inchaço posteromedial no terço distal da perna em plano axial. 

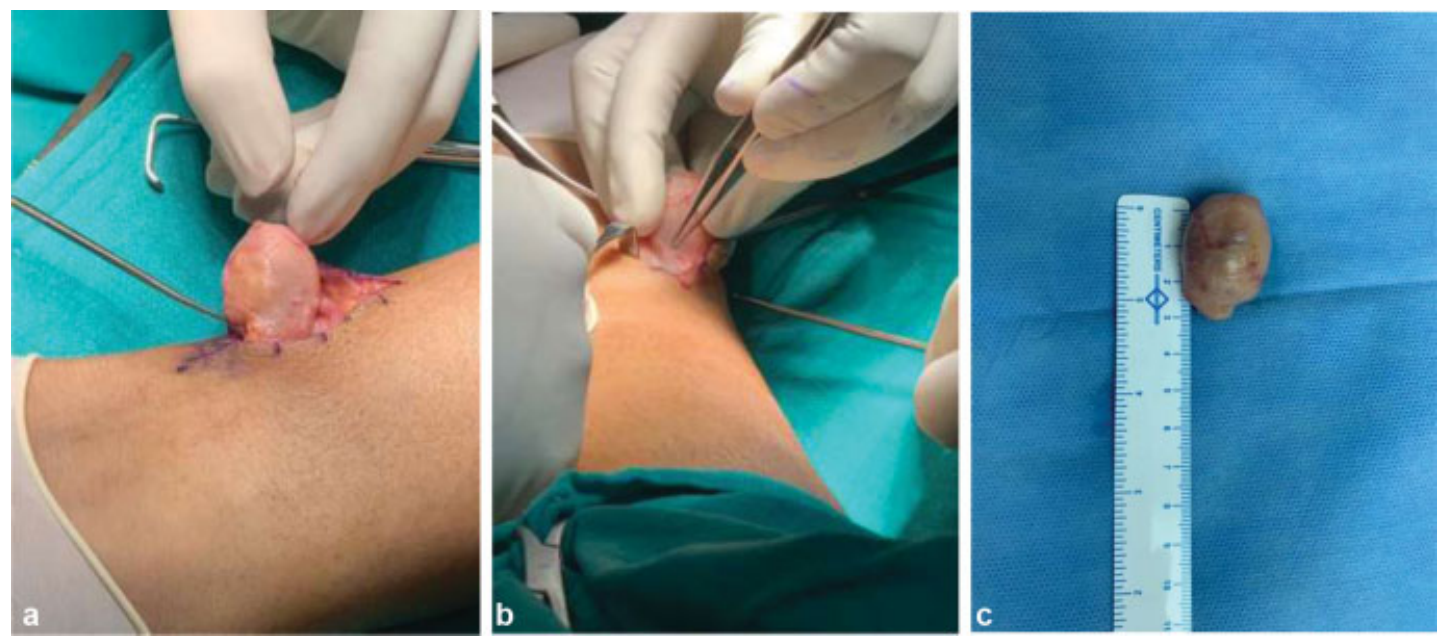

Fig. 2 (a) Imagem do intraoperatório apresentando tumor ligado ao tecido neurovascular subjacente e outros tecidos moles. (b) Dissecção fina das estruturas neurovasculares do tumor. (c) Medida da dimensão do tumor excisado.

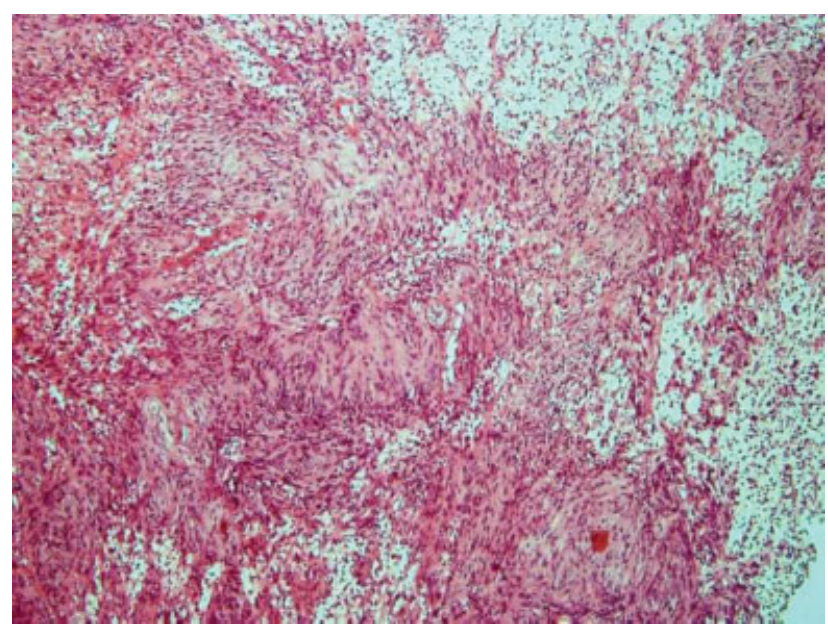

Fig. 3 Lâmina histopatológica mostrando tumor composto de áreas de células ovais a células espinhosas, com núcleos ovais finos e formação dos corpos de Verocay (tipo Antoni A) e área paucicelular solta tipo Antoni B.

\section{Discussão}

Schwanomma nas extremidades inferiores está limitado a menos de $10 \%$ de todos os casos, conforme estudo de Albert et al. $^{3}$ Nosso caso é raro, pois os resultados da pesquisa da literatura mostram muito poucos relatos de casos de schwannoma afetando o nervo tibial posterior.

A demora no diagnóstico é muitas vezes peculiar nos casos de schwanomma do nervo tibial. Nosso paciente foi operado após 15 anos dos primeiros sintomas. Atraso semelhante no diagnóstico, de até 10 anos, foi relatado por Ghaly em seu estudo. ${ }^{4}$ Smith e $A m i s^{5}$ relataram dor no pé por 8anos antes do reconhecimento de um schwannoma, enquanto Nawabi e Sinisi ${ }^{6}$ sugeriram que o tempo médio para diagnosticar o schwannoma era de 86,5 meses (mais de 7 anos).

A excisão extracapsular é a técnica comumente usada, ${ }^{7}$ que pode estar associada ao risco de desenvolver déficits neuroló- gicos pós-operatórios. Durante a dissecção tumoral, para reduzir o risco de danos aos fascículos nervosos, Hussain et al. ${ }^{8}$ propuseram a liberação do tumor, incisando a cápsula bem lateralmente ao caminho do nervo e dissecando-a circunferencialmente, com a cápsula epineural por trás, para atuar como cobertura protetora. No nosso caso, incisamos a cápsula no aspecto dorsal, pois sabíamos que o nervo estava no aspecto ventral. Isso foi seguido pela dissecção até o nervo e dissecção mais fina, separando-a do nervo pai.

Relatamos uma localização rara de schwannoma no nervo tibial posterior sobre $o$ aspecto posteromedial do tornozelo, administrado por excisão, sem danos neurovasculares.

\section{Conflito de Interesses}

Os autores declaram não haver conflito de interesses.

\section{Referências}

1 Adani R, Baccarani A, Guidi E, Tarallo L. Schwannomas of the upper extremity: diagnosis and treatment. Chir Organi Mov 2008; 92(02):85-88

2 Fletcher CD. Peripheral nerve sheath tumors. A clinicopathologic update. Pathol Annu 1990;25(Pt 1):53-74

3 Albert P, Patel J, Badawy K, et al. Peripheral Nerve Schwannoma: A Review of Varying Clinical Presentations and Imaging Findings. J Foot Ankle Surg 2017;56(03):632-637

4 Ghaly RF. Um neurilemoma do nervo tibial posterior não reconhecido por 10 anos: relato de caso. Neurocirurgia 2001;48(03): 668-672

5 Smith W, Amis JA. Neurilemoma of the tibial nerve. A case report. J Bone Joint Surg Am 1992;74(03):443-444

6 Nawabi DH, Sinisi M. Schwannoma of the posterior tibial nerve: the problem of delay in diagnosis. The Journal of bone and joint surgery 2007;89-B(06):814-816

7 Rockwell GM, Thoma A, Salama S. Schwannoma of the hand and wrist. Plast Reconstr Surg 2003;111(03):1227-1232

8 Hussain M, Jhattu H, Pandya A, et al. A precise excision technique for schwanommas. Eur J Plast Surg 2012;36(02): $111-114$ 